CHAPTER 4: Women's experiences of coping with the sexual side effects of antidepressant medication.

This manuscript was published in the journal of Psychology and Health, July 2014.

O'Mullan, C, Doherty, M, Coates, R \& Tilley, PJM. (2014). Women's experiences of coping with the sexual side effects of antidepressant medication. Psychology and Health, 29 (12), 1388-1406. http://dx.doi.org/10.1080/08870446.2014.940951 


\section{Chapter Overview}

This chapter is the author- accepted (post-print) version of the article published in the journal of Psychology and Health. Publisher copyright policies relating to this article are supplied in Appendix E. Co-author statements are provided in Appendix F.

This chapter presents the overall findings from the study and reports on the four broad themes, namely i) searching; ii) suffering in silence; iii) trying to resolve and; iv) accepting what is. The themes provide insight into the different strategies used by women to cope with the sexual side effects of SSRI medication and have practical implications for women on SSRIs and for clinicians, therapists and other relevant health professionals. The findings highlight the importance of contextualising these difficulties as part of an overall approach to improve the management and treatment of SSRI-related sexual side effects. 


\begin{abstract}
A growing body of evidence has highlighted the sexual side effects of selective serotonin reuptake inhibitor (SSRI) medication. Whilst most of the research has focused on the prevalence and treatment of sexual difficulties, little is known about how individuals cope with the SSRI related sexual side effects. The objective of this study was to explore women's experiences of coping with the sexual side effects of SSRI medication and interpretative phenomenological analysis (IPA) was employed for an in-depth exploratory study of a sample of ten women. Four broad themes emerged which are discussed under the following headings: searching, suffering in silence, trying to resolve and accepting what is. The themes provide an insight into the different strategies used by women to cope with the sexual side effects of SSRI medication and highlight the importance of contextualising these difficulties as part of an overall approach to improve the management and treatment of SSRI related sexual side effects.
\end{abstract}

Key words: SSRI, sexual side effects, females, coping strategies, qualitative 


\section{Introduction}

Depression is a leading contributor to the non-fatal burden of disease, and evidence suggests antidepressant drug use is increasing in developed countries (Saragoussi et al., 2012; Zhang et al., 2010). Although a variety of antidepressants are available, including tricyclics (TCAs), and monoamine oxidase inhibitors (MAOIs), selective serotonin reuptake inhibitors (SSRIs) are the most frequently prescribed antidepressant in Australia (Wong, Taylor, Ashby \& Robinson, 2010). This paper focuses on the side effects of SSRIs including fluoxetine (Prozac), paroxetine (Aropax/Paxil), sertraline (Zoloft), citalopram (Celexa), escitalopram (Lexapro) and fluvoaxamine (Luvox). SSRIs differ from older antidepressants in their chemical structure and method of action; the side effects of this newer medication are more tolerable making these a first line treatment for depression and anxiety (Moret, Issacc \& Briley, 2009). Whilst SSRIs are generally well tolerated, they are not devoid of side effects. Several authors have reported on treatment emergent sexual side effects and state how these adverse side effects are a common cause for nonadherence to long- term treatment (Basson, Rees, Wang, Montejo \&Incrocci, 2010; Serretti \& Chiesa, 2009). Widespread use of SSRls and concerns relating to adherence rates have prompted an emerging body of research into the sexual side effects (Basson et al., 2010; Grover et al., 2012) and have been the focus of a recent Cochrane review (Taylor et al., 2013).

As sexual difficulties may occur for a number of reasons, it remains difficult to obtain statistics relating to the prevalence of treatment emergent sexual difficulties resulting from this medication (Clayton \& Balon, 2009; Safarinejad, 2011). What is becoming evident, however, is that sexual side effects are more common than initially perceived. Studies have reported treatment emergent sexual side effects of over 50\% (Fisher \& Thomson, 2006; Grover et al., 2012; Serretti \& Chiesa, 2009). According to Basson et al. (2010), side effects were related to all aspects of sexual functioning but the main effects were loss of desire and delay of orgasm. As women are at increased risk of mental health problems, and have higher levels of SSRI use (Hollingworth, Burgess \& Whiteford, 2010; Zhang et al., 2010), recent studies have 
focused specifically on the treatment of SSRI related sexual difficulties in women in an attempt to improve quality of life and to increase adherence to medication (Demmyttenaere \& Jaspers, 2008; Safarinejad, 2011). To date, treatment and management approaches have included a number of strategies including drug holidays, natural supplements, switching antidepressants and augmenting antidepressant treatment with other medications including buproprion and sildenafil (Nurnberg et al., 2008; Safarinejad, 2011). In the Cochrane review undertaken in 2013, 23 randomised studies focused on managing sexual difficulties associated with antidepressant use were reviewed (Taylor et al., 2013). Twenty-two of these studies investigated the addition of further medication to treat sexual difficulties and one study investigated switching to an alternative antidepressant. According to this report, augmenting antidepressant treatment with buproprion at high levels appeared to be the most promising strategy for treating women, however, the authors called for more evidence to guide the management and treatment of sexual difficulties (Taylor et al., 2013).

Numerous scholars have critiqued the biomedical approach to sexuality research (Farrell \& Cacchioni, 2012; Moynihan, 2003; Tiefer, 2012), yet this approach has dominated most of the research into SSRI related sexual difficulties (Safarinejad, 2011; Taylor et al., 2013; Williams et al., 2010). One major criticism of this approach is that it fails to consider the social and cultural construction of sexual experience. Dworkin and O'Sullivan (2007, p.106), revealed how traditional sexual scripts in Western culture which offer men 'greater sexual freedom and rights of sexual determination' than women, can affect sexual experiences and interactions. Weiderman's (2005) article, relating to male and female sexual scripts in Western culture, highlighted how women have felt pressured to follow traditional sexual scripts, adjusting their behaviour to meet cultural and social norms. Another limitation of the biomedical approach, according to Bahrick and Harris (2009, p.136), was that psychosocial aspects of antidepressant related sexual difficulties have been largely ignored; little is known about how the addition of sexual difficulties may potentially 'complicate and confuse the clinical picture, exacerbate client distress and destabilise intimate relationships.' From the literature review, it became obvious that investigating women's subjective experiences of coping with SSRI related sexual difficulties was necessary. As such, the focus of this research was on the coping aspect of heterosexual women's experiences and the research question was, "What 
are the lived experiences of coping with the sexual side effects of SSRI medication?" The findings from this research provide further insight into the types of strategies that may be relevant for women on antidepressant medication and for clinicians, therapists and other health professionals, in order to improve the success of and satisfaction with SSRI treatment.

In this study, the term 'sexual difficulty' was used. A definition was not provided as each participant brought her own understanding and identification of what sexual difficulty meant to her. Whilst female sexual difficulties relating to desire, arousal, orgasm and pain are currently grouped under the term 'sexual dysfunction' in the most recent Diagnostic and Statistical Manual of Mental Disorders, Fifth Edition (DSM-5 ${ }^{\mathrm{R})}$ (American Psychiatric Association, 2013), sexual dysfunction is a contested term which aligns with a medicalised view of sexual difficulties. This approach has been criticised for pathologising women and often disregarding the social and cultural contexts of sexuality (Farrell \& Cacchioni, 2012; Tiefer, 2012).

\section{Method}

\section{Methodology}

The study used Interpretative Phenomenological Analysis (IPA) as a research approach. Three key areas of philosophy of knowledge namely, 'phenomenology, hermeneutics and idiography' have informed this approach (Smith, Flowers and Larkin, 2009). IPA has been used for over a decade to capture women's experiences of intimate topics relating to their sexual health (Holt \& Slade, 2003; Lavie \& Willig, 2005; Marriott \& Thompson, 2008) and was therefore particularly suited to this study as it captured the unique voices and experiences of women and situated those experiences within a social and cultural context.

\section{Sampling}

The intention was to recruit a purposive sample - that is, using criteria relevant to the research question, rather than necessarily being representative of the population living with SSRI related sexual difficulties. Whilst recognising that it is difficult to ensure complete homogeneity, especially with respect to factors such as relationship dynamics, a degree of homogeneity was sought by recruiting potential 
participants through the application of inclusion criteria. This criteria included the following i) Australian females under 45 years old who were currently in a heterosexual relationship and who had been taking SSRIs for longer than 3 months; ii) females who self described as experiencing sexual difficulties that were believed to be attributable to SSRIs; iii) females who were experiencing sexual difficulties that were causing problems or distress to her and/or her partner. The authors selected 45 years as the appropriate cut off for this study as prevalence and treatment rates of affective and anxiety disorders decline rapidly after this age (Hollingworth, Burgess \& Whiteford, 2010).

Participants for this study were recruited via a mental health website (depressionnet.com), social media sites and snowball techniques (Liamputtong, 2013). As reported by Moreira, Glasser, King, Duarte and Gingell (2008) and Shifren et al. (2009), women have often been reluctant to seek help for sexual problems, therefore, we did not recruit through health professionals or clinics. Interested women were emailed a brief questionnaire to capture demographic information and to ensure inclusion criteria were met. Those who met the inclusion criteria (ten women), were invited to participate in the study.

Whilst no definitive criteria exist for sample size in IPA, its commitment to an idiographic approach results in such studies generally being conducted with small sample sizes of ten or less (Smith et al., 2009). The authors perceived that the sample of ten women adequately captured patterns of similarity within the group whilst recognising the particularities of individual lives.

\section{Data Collection}

Prior to data collection, ethical approval was obtained from the relevant university human research ethics committee. Data were collected through two semistructured interviews comprised of questions that related to heterosexual women's experiences of coping with the sexual side effects of SSRI medication. The interview schedule comprised of eight open-ended questions, which were informed by the literature review and professional experience of the first author. Informed consent was obtained from each woman prior to the first interview. First interviews were face-toface and lasted between 1 hour and 1 hour 45 minutes in length. Follow up interviews were between 45 minutes and 1 hour 15 minutes. During this second interview, the lead researcher and each woman reviewed the transcript and discussed emergent 
themes arising from the first interview to ensure accurate interpretation of the participant's experience. In addition, women were given the opportunity to further elaborate on their lived experiences; this led to enriched data as women had been given an opportunity to reflect on their experiences after the first interview.

\section{Data Analysis}

Data analysis followed guidelines put forward by Smith et al. (2009), and involved the following: reading and re reading the transcript, initial noting, developing emergent themes, searching for connection across emergent themes, moving to the next case and looking for patterns across cases. As this research was interpretive, the lead researcher's comments whilst analysing and noting emergent themes, moved beyond descriptive words and phrases to a deeper conceptual analysis to acknowledge social and cultural contexts. Upon completion of analysis from both interviews, a description of the themes was given to each woman to check the interpretation. Once data analysis was completed for all cases, the next stage involved analysing for recurrent themes across all ten cases; this resulted in four super- ordinate themes. Eleven corresponding sub-ordinate themes were nested within these super-ordinate themes. The super and sub-ordinate themes are discussed under Findings.

\section{Reflexivity}

Within IPA, the researcher plays an active role in interpreting data. Smith et al. (2009) highlighted the importance of reflexivity (where the researcher reflects on how their experiences may influence the research). As the lead researcher had experienced the sexual side effects of SSRI medication, the experience meant that the interviewer was conducting the research from an insider emic perspective. She briefly touched upon her experiences of sexual difficulties with each woman at the beginning of the first interview while emphasising that the purpose of the study was to explore their individual stories and unique experience of coping. Women were given the opportunity to ask questions about the researcher's experiences at the end of each interview.

During data collection, the researcher utilised a reflexive journal to acknowledge her preconceptions and assumptions before and immediately after each interview. By attempting to set aside her preconceptions immediately before 
the interview, the researcher felt she was able to listen attentively to the participant's story rather than being distracted by her own experiences. Smith et al. (2009) highlight the importance of attentive listening and engagement with the participant, and argue that such close attention during the interview process limits the influence of the researcher's preconceptions. Throughout the data analysis phase, reflexive journaling enabled the researcher to reflect upon the data to ensure it reflected the experiences of women rather than her own prior to documenting conclusions. The researcher also obtained the support of a colleague who questioned whether assumptions had been made and highlighted potential areas of bias, which may have been influenced by the researcher's history and perspective.

\section{Findings}

The following is an account of the lived experiences of women coping with the sexual side effects of SSRI medication. The four separate but overlapping super-ordinate themes and eleven sub-ordinate themes that emerged from the data analysis are supported with quotations from the women's accounts. At various stages throughout their journey, women adopted one or more of the coping strategies and the combination of approaches used by the women tended to vary over time. Pseudonyms were assigned to protect each woman's identity.

\section{Searching}

This theme describes the processes women engaged in as part of their coping mechanism when first experiencing what they identified as sexual difficulties associated with SSRI medication, and at times throughout their journey. The theme searching, included two sub-ordinate themes i) searching for answers and ii) searching for validation.

\section{Searching for answers}

A search for reasons behind the sexual side effects frequently underpinned the coping experience of most women in this study, with women commonly commenting on how GPs had neglected to inform them about the side effects when the medication was prescribed. Consequently, these women particularly struggled with sexual side effects at an early stage in their journey, and frequently questioned 
whether they had psychological problems and/or whether their experiences were normal.

I guess for me, finding that information [on the internet], that was a real turning point, I finally had my answer. ......if you go back to the leaflet in the medication it says that you may experience side effects but there's about 5 million side effects on there. Initially I thought they're just covering their back you know just in case, and I thought, well you know, reality is it's probably 1 in a million chance that you're going to have sexual sides effects, and then I started reading about it and I thought... hang on a minute, the amount of women that are experiencing this is not one in a million, there are thousands of us. (Nadia, 42)

The women talked about the difficulties of sharing their problems due to the perceived public stigma of mental illness, and the sensitive and emotive nature of their problem. As women were unable to communicate with friends or trusted others, information about their side effects was predominantly sought from the internet. By searching on the internet, women discovered sexual side effects were frequent amongst users of SSRIs. For these women, having a legitimate reason for their sexual difficulties and finding they were not alone with their experiences proved a positive turning point:

Once I realised that the sensation wasn't there, I started to freak out, I did actually quite freak out about for a while and then I think I Googled about possible female side effects, and I didn't find much on it, but found something, there was something. I don't know if there was a forum or something, where I kind of read about women not being able to reach orgasm. At the time, yeah I'm thinking relief, just relief that at least I knew why it was happening, it wasn't just me, I wasn't some kind of freak. (Mandy, 38)

The primary motivation for searching for information stemmed from a desire to protect current relationships. Having answers about the sexual side effects had positive implications for both their relationship, as well as their identity as a sexual person: 
When I did eventually find the articles on the net, I would show him and say "Look it's not just me, lots of women are going through this. It's not your fault, it's got nothing to do with you, it's got nothing to do with our relationship" to help him understand. Because I guess you worry, you think well you know, they might think that I'm frigid or I'm not interested in them anymore. I guess I don't want him having a complex. (Tahlia, 26)

The majority of women felt having more information at an earlier stage, would have assisted them in coping. Alison, who had received information from her general practitioner, talked about feeling prepared and her experiences highlighted the importance of knowing about the side effects in advance:

I remembered exactly what she had told me um, so (pause) I guess to an extent it did help because you know I sort of had that awareness up front that this could be an issue..... when it actually came up as an issue I was kind of a bit more prepared for it. If she hadn't even said those couple of sentences to me I would be thinking "What the hell is wrong? What's going on? I don't understand this at all?" um, and be pretty confronted and scared by that I guess. (Alison, 29)

\section{Searching for validation}

For the women, having their sexual concerns validated played an important part in helping them to cope. They felt the difficulties were serious enough to consider seeking professional help but their experiences of not having concerns validated by GPs had an impact on how they understood and hence coped with difficulties initially. Charlotte mentioned about 'psyching herself' to build the courage to raise the issue with her GP, her comment below typifies the dismissive comments and reactions experienced by the women in this study:

When I eventually went to the Drs, it's like "Oh you know, it's a typical women thing. You've got kids, life's stressful deal with it". Well l've been through a lot more stress in my life and it didn't do that to my libido! I asked him if there was 
a Viagra for women or something - he laughed and said he'll get back to me that's 6 months ago and I'm still waiting. (Charlotte, 45)

Furthermore, women reported that GPs appeared unwilling to accept their sexual side effects as a legitimate problem. This led them to seek validation and support through online discussions forums. Nadia commented:

But deep down l've always been really angry about that [GPs dismissing sexual concerns] and thought, "No that's not quite right." So I guess validating that and finding that other women on there [internet] also are saying you know "I haven't got a good sex life and I want to do something about it" makes me feel better. (Nadia, 42)

\section{Suffering in Silence}

For the women in this study, the theme suffering in silence emerged as a coping strategy and captured the women's sense of not being able to communicate about their experiences. The sub-ordinate themes of avoiding sexual encounters, protecting one's partner and protecting one's self were often intertwined, but are discussed separately to enhance conceptual clarity.

\section{Avoiding sexual encounters.}

The women coped with sexual side effects by avoiding sexual encounters either through passive or proactive avoidance strategies. Whilst most women viewed this strategy as temporary, and recognised they were not adequately addressing the problem, Mandy considered this to be an appropriate strategy for a short term problem:

Well my husband works away so I mean his last stint away was for four weeks and I really could not have been interested, it was the best time of my life (pause) because he wasn't home annoying me about sex. If I could keep avoiding it for 4 weeks, wow, before I know it, l'll be off the medication again! (Mandy, 37) 
Other women talked about the importance of not wanting to reject openly their partner's advances; hence, a number of proactive avoidance strategies were used which enabled women to avoid sexual activity without actually saying 'No':

l'd go to bed half an hour before him so l'd be asleep when he came in, or half an hour after so that he'd be asleep. Just so I could avoid sex in any way. (Charlotte, 45)

One woman talked about avoiding all forms of intimate contact, fearing such encounters would automatically lead to sex:

Sometimes I just feel like a kiss and cuddle, especially at night, but then I think "Am I leading him on?" 'cos I know I don't want sex. It's hard, I still want to be intimate but I'm scared because I know it will lead to other stuff. (Sonia, 30)

Interestingly, the avoidance strategies put into place by the women, highlighted again, the separate but overlapping nature of sub-ordinate themes grouped under 'Suffering in Silence'. By adopting avoidance as a coping strategy, women succeeded in protecting their partners (from rejection) and protecting themselves (from an unwanted sexual experience).

\section{Protecting one's partner.}

Having sex was perceived as being central to the women's relationships in this study. Believing their partner would be upset if there was a sexual problem, many women were compelled to protect their partners and viewed the problem as their 'own problem' as opposed to a shared problem. More than half of the women, predominantly those who had been taking medication for less than one year, made a conscious decision to cope with sexual difficulties alone. Most women held the view that they were obliged to have sex with their partners thereby placing his sexual needs as more important than their own:

I didn't want to tell him, that when I was having sex with him l'd rather be sleeping. That would have just killed his ego. It would have been very detrimental to him. There was no way I could say that I'm just going through with this just for your benefit. (Helen, 23) 
Women also talked about the need to reciprocate as part of a healthy relationship and to be sensitive to their partner's needs:

My husband is so wonderful and I feel so guilty that I don't have a libido for him. I do feel obligated though, he's so gentle and kind - sometimes after sex I just end up crying, but I manage to hide it - he's my husband, I love him, so I let him do it. (Charlotte, 45)

Faking orgasm was a common coping strategy to manage the potential relationship impact of the sexual side effects. Although many women talked about feeling guilty and even deceptive within their relationship, in contrast, one woman considered this to be an acceptable and effective strategy:

It works well for our situation, I mean, you can fake sexual pleasure, but you can't fake the weight gain can you? (Mandy, 38)

Reasons why women engaged in non-pleasurable sex were driven by a need to protect their partner and the relationship, but also to protect themselves from unwanted consequences.

\section{Protecting one's self.}

Women revealed how they chose to be silent about their experiences as a selfdefence strategy to protect themselves from potentially negative consequences. Two women described how they chose not to communicate with their partner for fear their partner's reaction would lead to unwanted consequences:

I suppose there's a small fear that he would say "Oh go off those antidepressants that's crap." You know, "You shouldn't have to deal with it, go off them." But the thing is, is that I'm getting so many good benefits, and I don't want to yet, but I am planning to eventually. (Mandy, 38)

If I speak to him, how do I put this? He's a typical truck driver - you know, take a spoon of concrete and 'Harden the Fuck Up'. If they're (the medication) doing that to you, just come off them. Of course, I can't do that. (Charlotte, 45) 
Women often emphasised the importance of sex within their relationship, and mentioned the need to hide their sexual difficulties for fear they would illuminate other problems within their relationship or their partners would look elsewhere for sex:

I think generally, that would be a fear of whether to communicate that issue [with my husband], 'cause if you bring it up, you know, are they going to go elsewhere type thing. Do you know what I mean? Have affairs and stuff like that? (Mandy, 38)

Suffering in silence, and the high levels of secrecy surrounding the use of SSRIs appeared to be fuelled by the perceived public stigma of mental health problems and fear of being discriminated against. Women talked about being able to protect themselves from the negative public image of mental health problems and the ramifications in terms of their daily interactions and experiences. In Phoebe's case, she applied corresponding stereotypes and prejudices to herself when explaining her reluctance to communicate with others:

It's not something you go "Hi, how're you? I'm on anti-depressants". You know people will turn and walk the other way and go "Well you're screwed or something" - that's what they think - like you're an axe murderer or something. (Phoebe, 40)

\section{Trying to resolve}

The theme trying to resolve included self-help strategies aimed at trying to fix or at least minimise sexual side effects of SSRIs. Sub-ordinate themes included altering medication, communicating with partner and taking steps to enhance sexual pleasure. All women, with exception of one, attempted to fix or at least try to resolve the problem and increase sexual pleasure; however, the type of approach was strongly influenced by length of time on medication. Women who had been on the medication for longer than two years used a combination of three approaches.

\section{Altering the medication}


For women who had been on medication for more than two years, altering the medication was identified as one of the major strategies. Many women adopted a self-help approach to altering the medication, using a range of different strategies including, taking drug holidays (a brief period where the woman stops taking the SSRI to regain sexual feelings), reducing the dosage and quitting the medication in an attempt to restore sexual feelings. Julie said:

I've resigned to the fact that, it's almost like being on par to being a diabetic, I need the insulin to just keep functioning on a day to day basis and, um (pause) um, and yeah, it's also led me to play with the dosage as well and try and decrease it so I can get some sexual function back, um, yeah. (Julie, 44)

Nadia described how she stumbled across this strategy and highlighted how she successfully self-managed her dosage of medication to suit her particular situation:

I forgot to bring my pills with me, and I started to experience really strong sexual dreams, and I almost like had an orgasm, it woke me up and I thought "oh" I've got these sexy feelings back again that's really weird. So I guess I figured on my own that if I stopped taking the medication for a couple of days those sexy feelings would come back again. No one told me about this, but then again no one told me about the sexual affects either. So I kind of cottoned on to this idea that if I have a bit of a break then I'm more likely to have an orgasm or for sex to be more pleasurable. So I guess now what I do is I guess try to anticipate when we might be more likely to have sex and I just stop taking the medication a couple of days before. (Nadia, 42)

Other women disagreed with the idea of self-managing their medication, highlighting the importance of taking the medication correctly and citing the fear of a relapse as a major reason for not altering the medication. This was the case even if they believed this strategy could work for them:

I did hear that you could take a few days off on some of them[ medication], I just wouldn't, couldn't even think about that, no way, I mean this sucks, but it does work and there's just no way I ever want to risk get back to where I was. It was not a good place. (Helen, 23) 


\section{Communicating with partner}

In contrast to the theme suffering in silence, some women on medication for more than two years, communicated with their partner about the sexual difficulties they were experiencing to resolve their sexual problems after other coping strategies had been attempted. For these women, communication with their partner was identified as being a necessary component of a longer-term coping strategy:

It really does, um get in the way of your relationship and um, yeah it does. You do have to talk a lot about it and you do have to communicate with your partner about it. ...and get across to them that it's not them, it's you, it's these pills. It's yeah, it's not them, they're not less physically appealing or less effective in the bedroom, yeah. (Julie, 44)

Lisa, who described how she finally opened up and started to communicate about both her mental health problems and the associated side effects of the medication, echoed this point. In her case, communication was triggered by a major depressive episode:

So it wasn't until I hit the ground in December last year where I went off the medications and then I had a massive terrible episode, I nearly ended up in hospital and then obviously he saw me. Like he saw me, he saw the deal, we saw what I was like and I honestly thought he was going to dump me but he didn't. He was fantastic, and that's when after that I've been more open with him about it. It's only the past 3 months I've been this open about the medication, how it wipes out the sex feelings, the everything really, but it has been so much better since l've been open. (Lisa, 44)

\section{Taking steps to enhance sexual pleasure}

The women commonly reported their desire to experience sexual pleasure again; however, they recognized that sustained efforts were needed to make this happen. Women sought to enhance pleasure by using sex toys, pornography, masturbation, changing sexual positions and trying herbal supplements. For some women, sexual 
difficulties were considered to be a shared problem rather than the woman's problem; hence, this was a strategy that involved open and honest communication and cooperation between both partners:

Um, I don't know, I think in our case or my case l've just become more aware of what does really work for me, the big points that work for me, so I suppose not being afraid to (pause) use sex toys, pornography or anything else that particularly works for me. Um, (pause) you know and because my partner is aware, he doesn't feel that it's um, his failure, it's just that this is what we have to do at the moment to make it work. So we do that. (Tahlia, 26)

For other women, the search for sexual satisfaction involved trying to resolve the issue on their own:

Um, well I guess this is a bit uncomfortable to talk about but, you know there are certain positions where I know I can reach orgasm much quicker and easier so I kind of move my body into that position, you know, and it does work sometimes. (Alison, 29)

I did search on the internet for potions and supplements and stuff - I even bought Horny Goatweed, that Gingko Biloba is meant to work for sexual problems too, but you have to take a lot of it I think. (Lisa, 44)

\section{Accepting what is}

A further theme, particularly amongst women who had been on medication for over two years, related to acceptance of their particular situation. This theme included three sub-ordinate themes i) counterbalancing the positive and negatives of SSRIs ii) embracing the positives in the relationship and iii) altering expectations about how sex 'should be'. Sub-ordinate themes two and three were more commonly used as a strategy by women in longer- term relationships. Acceptance did not imply that the women have given up hope. This is exemplified by a comment from Nadia: 
I don't see this getting any better so I don't think there is going to be a magic solution, I really don't believe there is going to be a pink Viagra or a pill that we are going to be able to pop that makes everything better. I'd love to think there would be and that would give other women and myself something to look forward to. I don't think that's gonna happen but every now and then I do jump onto Google in case there is something new on the market that might help. In terms of how I cope overall though, I guess I focus on the positives in my relationship and what's working well and what's good. (Nadia, 42)

\section{Counterbalancing the positive and negatives of SSRI medication}

Women in the study acknowledged the benefits from the medication, and although the sexual side effects were problematic, at least two women chose to focus on benefits:

Sex isn't as enjoyable as it was before I was on it [the SSRI] but I'm actually feeling better, like I'm feeling well so I kind of balanced it I guess you know with kind of going well yeah this side effect does really suck but look at what I'm gaining as well. (Alison, 29)

In terms of coping, I think um, just um, acceptance is the thing that works for me the most, yeah. The medication has worked wonders for me, after my attempted suicide, well.... I don't want to go there again you know so the sex stuff, well I kind of just deal with it. (Julie, 44)

Others highlighted how sex had been relegated as less important, while they focused on recovering from either anxiety or depression. There appeared to be a high level of acceptance that the medication would have positive and negative outcomes associated with it:

I guess you have to sort of accept that you aren't going to have great sex...well you have to accept that I think. I think there's no alternative, I think, you know well what are you gonna do? Stop the medication altogether? Well that's not the right thing to do is it, I mean that stuff works.... it keeps me sane do you 
know what I mean? So you have to, you have to just take the positives with the negatives don't you? (Phoebe, 40)

\section{Embracing the positives in the relationship}

As part of an ongoing coping strategy, women in longer-term relationships described how they had started to focus on positives within the relationship, particularly the relational aspects of sexuality such as companionship and intimacy, rather than the physical act of sex. Mandy stated:

I'm lucky, I guess, I actually get a lot out of just cuddling and kissing and being affectionate and the big thing that we always hear about is you know when the man puts the garbage out, you know I love all that stuff (both laughing). You know he's been home the last week and he's been making breakfast every morning and I find that really just wonderful. And to me that's more than sex. (Mandy, 38)

Similarly, Phoebe noted:

At the end of the day, the sex you know, only goes for what minutes? But it's that other stuff, hugging, intimacy, talking, helping each other - there's all that sort of stuff happening which is still really important for both of us. (Phoebe, 40)

\section{Altering expectations about how sex 'should be'}

The women in this study discussed how they lowered their expectations about sex, and used positive self-talk to challenge social and cultural expectations of what sex should be like:

I guess I have a tendency to think back to how it was in my 20's and how amazing it was. And maybe that's not realistic, even when you're not on Aropax. I mean, how many of my 41 year old friends are having amazing sex, hanging from the chandeliers and multiple orgasms three times a week? Just 
not happening, I don't think, you really need to just accept that I guess. (Nadia, 42)

Sonia commented how her and her partner's expectations about sexual frequency were altered as a result of their current circumstances. She also used positive selftalk:

When I had brought up the topic to with him [about the infrequency of sex], he just said "Oh well this is how it is now with the kids and.." yeah, so I suppose we're kind of just accepting that this is how it is, and how it would be, even if I wasn't on medication. (Sonia, 30)

\section{Discussion}

Managing and treating the sexual side effects of SSRIs have presented a challenge to women, clinicians/ health professionals and researchers; to our knowledge, this is the first qualitative study to investigate how women cope with such side effects. Four discrete but overlapping super-ordinate themes emerged during analysis i) searching, ii) suffering in silence, iii) trying to resolve and iv) accepting what is. Women's experiences of coping with sexual difficulties were similar to those reported by Mitchell, King, Nazareth \& Wellings (2011), that both men and women manage sexual difficulties by using a number of coping strategies simultaneously but a combination that varied over time. The choice of coping strategy for women in this study was commonly influenced by the length of time on medication, the partnership context and external influences, particularly the socio-cultural context of their experiences. Consistent with findings from other studies into female sexual difficulties (Ayling \&Ussher, 2008; Holt \& Slade, 2003; Marriott \& Thompson, 2008), difficulties experienced by women in this study carried personal and relational meanings which impacted on their self-identity and influenced the type of strategies employed to cope with side effects.

Whilst coping strategies have been classified in a number of different ways (Brandtstadter \& Renner, 1990; Suls \& Fletcher, 1985, Lazarus and Folkman, 1984), the strategies employed in this study, fit well with the two broad coping classes put forward by Lazarus and Folkman (1984), namely, problem and emotion-focused coping. Problem-focused coping involves efforts to alter the situation or 
circumstances; in this study, the efforts included the strategies of 'searching' (for information and validation) and 'trying to resolve' (the problem). Whilst problemfocused coping strategies are considered to be adaptive or associated with positive coping actions (Levahot, 2012), the debate about whether a strategy is adaptive or not is contested. Indeed, studies have argued that all strategies potentially have an adaptive purpose (Bergvik, Sorlie \& Wynn, 2010; Mitchell et al., 2011). Emotionfocused coping, on the other hand, involves efforts to manage emotional rather than physical distress associated with the situation or circumstance, and tends to include both active (generally perceived to be adaptive) and avoidant strategies (considered to be maladaptive or detrimental) (Levahot, 2012). In this study, emotion-focused coping comprised the active strategy of 'accepting what is' and the avoidant strategy of 'suffering in silence'. Although avoidant approaches (faking orgasm, avoiding sexual encounters, not communicating with partner) could typically be labelled as maladaptive, the findings revealed they did serve an adaptive purpose for those women who were on medication for two years or less.

\section{Searching}

The theme searching was identified as a key coping strategy in this study; women frequently reported that they searched for both information and validation to help make sense of their experience and to interpret their situations. This finding is consistent with other studies which have focused on living with an intimate problem which impacts upon female sexuality (Holt \& Slade, 2003; Marriot \& Thompson, 2008). Once women had an explanation and could attribute their difficulties to SSRI medication, they reported feeling relieved and more capable to adjust to the sexual side effects. This finding corroborates the ideas of Happell, Manias and Roper (2004), who highlighted how individuals with mental health problems want to know about side effects from their medication in order to be better prepared. It also supports later research by Bahrik and Harris (2009), and Quinn, Happell and Browne (2012) that called for individuals to be better informed about the sexual side effects of antidepressants given their pervasiveness and potential to impact upon treatment and quality of life. Indeed, Mitchell and Selmes (2007) suggested that increased knowledge about side effects of medication may improve adherence rates in individuals with mental health problems. 


\section{Suffering in Silence}

The theme suffering in silence included three strategies and the idea that relationships were at risk, was central to those selected. The sub-ordinate themes of protecting one's partner and protecting one's self were identified by Hinchliff, Gott and Wylie (2012), who reported that women with sexual difficulties used strategies to avoid sexual encounters to protect their partner from the disappointment of being let down but also to protect themselves from the consequences associated with actively rejecting their partner. Social scripts privileging men's wants and needs in a sexual relationship also strongly impacted most of the strategies used by the women in this study, particularly with respect to suffering in silence when they reported faking orgasm, avoiding sexual encounters and choosing not to communicate with their partners. Whilst individualistic and reductionist approaches to women's sexual difficulties have been critiqued (Cacchioni \& Tiefer, 2012; Tiefer, 2012), the women in this study attributed their sexual difficulties to SSRI medication, and viewed the problem as their 'own problem' as opposed to a shared problem. This is not surprising given the current biomedical approach to female sexual problems, which emphasises the importance of individual factors and 'renders the complexity of factors affecting women's sexual lives less visible' (Nicholls, 2008, p. 516; Tiefer, 2012).

Our findings concur with studies that argue the socially constructed nature of women's sexuality, and highlight the dominance of the male sexual drive discourse in Western culture (Ayling \& Ussher, 2008; Davison \& Huntington, 2010). The findings further our understanding of how social and cultural factors, such as dominant discourses of sexuality can influence how women cope with sexual side effects of SSRIs. Additionally, reluctance to communicate with their partner and others also featured prominently, and the women talked about how the perception of public stigma relating to mental health problems and/or a sexual problem led them to suffer in silence. Prior studies have noted that individuals with a stigmatised condition have been more likely to self-manage information or, to at least assess the costs and benefits of disclosure to others, citing risk, embarrassment and impact on social identity as key factors (Davison \& Huntington, 2010; Goffman, 1963; Holt \& Slade, 2003). 


\section{Trying to Resolve}

Women on long-term medication frequently attempted to resolve sexual difficulties. Women attempted to self-manage the problem and did not seek help or report it to a clinician, therapist or health professional because of previous inadequate helpseeking experiences, and embarrassment about the sensitive nature of sexual difficulties. This finding supported the work undertaken by Rosenberg, Bleiberg, Koscis and Gross (2003) which reported that $80 \%$ of women with mental health problems did not seek formal help for sexual side effects of medication. Despite the sexual side effects, women in this study continued to take their medication. However, those women on longer-term medication altered the dosage or took a drug holiday in an attempt to restore sexual feelings, which are consistent with strategies reported through biomedical research aimed at managing sexual side effects (Clayton \& Balon, 2009; Schweitzer, Maguire \& Ng, 2009).

Although switching antidepressant medication has been highlighted by Baldwin (2004) and Clayton and Balon (2009) as a legitimate strategy to help manage antidepressant related sexual difficulties, surprisingly, none of the women in this study considered this to be a realistic strategy. Our findings revealed that women made a conscious decision to continue their prescribed medication highlighting the perceived benefits and fear of potential relapse, which supports the work by Clayton and Balon (2009) that reported individuals might be fearful of therapeutic failure with a new drug. Other sub-ordinate themes aimed at trying to resolve the problem included communicating with their partner and taking steps to enhance sexual pleasure. Although prior studies have highlighted how increased communication with a partner has positively impacted how women cope with sexual difficulties (Hayes, 2008; Mitchell et al., 2011), it was somewhat surprising that the women on medication for less than 12 months in this study chose not to communicate with their partner. This was a deliberate strategy to protect both their partner and themselves.

\section{Accepting What Is}

For women on long-term medication, acceptance of their situation helped them to cope with the sexual side effects. Attempts to embrace the positives within their relationship and to change expectations about sex were commonly employed, findings, which support the study on coping with sexual, side effects conducted by Mitchell et al. (2011). These two coping strategies fit with the 'Good Enough Sex 
Model' proposed by Metz and McCarthy (2007), which encourages positive and realistic expectations about the role and meaning of both intimacy and sexuality across the lifespan. Proponents of this model argued such a perspective can provide a positive and genuine foundation for relationship and sexual satisfaction (McCarthy \& McDonald, 2009; Metz \& McCarthy, 2007). Our findings also support calls by other researchers to consider a therapeutic approach to managing female sexual difficulties, an approach based on questioning and challenging rigid sexual scripts and normative heterosexual practices (Farrell \& Cacchioni, 2012; Mc Cormick, 2010; Mitchell et al., 2011). Consistent with findings from Sutherland's (2012) study into women's experiences of sexual pain and discomfort, the women in this study had not given up hope that their situation would eventually improve; indeed those who employed acceptance as a coping strategy also continued to search for information in the hope of finding a solution.

\section{Implications and Limitations}

\section{Implications}

The findings from our study have practical implications for women on SSRIs and for clinicians, therapists and health professionals, and provide further insight into the types of strategies that could be promoted to women in order to improve the success of and satisfaction with SSRI treatment. Our findings call for open and proactive communication between clinicians/health professionals and women with respect to sexual side effects, and highlight the importance of having sexual concerns validated. An authentic commitment is needed to ensure that clinicians, therapists and health professionals have the necessary education and skills to work effectively with women to enhance the management of sexual difficulties; the authors suggest such issues are highlighted by relevant professional associations and included in professional development programs. It is also evident from this study that women's lack of knowledge relating to the sexual side effects of SSRIs impacted on their ability to cope. It is imperative, therefore, that information materials, which outline sexual side effects and common concerns, be developed and made available in a variety of formats.

Our findings also emphasise the need to recognise and address psychological, social and cultural factors, which may have an influence on how women cope with sexual side effects. Effective management of SSRI related sexual 
difficulties calls for a collaborative approach, which moves beyond biomedical interventions relating to the treatment of sexual difficulties. A psychological intervention, which recognises the influence of social and cultural context on women's experiences, may be effective in helping individual women to work through the influence of context on their experience, explore multiple meanings they may have around sex and help develop a positive sense of themselves as women. Such an approach also needs to be complemented by couple therapy, which explores relationship dynamics and how best to work with them to achieve mutually satisfying outcomes within the relationship. Understanding the complex interaction among the various psychological, cultural and social factors is essential for helping women to effectively manage the sexual difficulties associated with SSRIs and to ultimately improve treatment outcomes.

\section{Limitations}

The limitations to this study include the relative homogeneity and self-selected nature of the sample. The women in the study were purposefully selected to ensure a degree of homogeneity and to enable us to explore the phenomenon of coping with SSRI related sexual difficulties across a particular target group (heterosexual, in a relationship, under 45 years old). Hence, the findings cannot be generalised to all women who experience SSRI related sexual difficulties. Indeed, the diverse age range of women in the study (23 to 45 years) further limits this study, as the potential differences in sexual experiences across the lifespan were not addressed.

Furthermore, it is also probable the women who chose to participate in the study had reached a stage of adjustment, as they were willing to talk openly about their coping experiences. Women who were struggling to cope may not be represented here.

The researchers recognise that this study does not represent the experiences of all women who experience SSRI related sexual difficulties; however, the purpose was to provide a detailed exploration of experiences from individual perspectives.

\section{Conclusion}

This study has captured the shared elements and unique voices of women who are coping with the sexual side effects of SSRI medication and has situated their experiences within a social and cultural context. It has provided an insight into what 
coping strategies women use, factors influencing choice of coping strategy, and how women use different strategies to manage the sexual side effects of SSRIs.

Furthermore, it has illuminated the importance of contextualising these difficulties as part of an overall approach to improve the management and treatment of these sexual side effects.

\section{References}

American Psychiatric Association. (2013). Diagnostic and statistical manual of mental disorders (5th ed.).Washington, DC: American Psychiatric Association.

Ayling, K. J. M. \& Ussher, J. (2008). "If Sex Hurts, Am I Still a Woman?" The subjective experience of vulvodynia in hetero-sexual women. Archives of Sexual Behavior, 37(2), 294-304.

Bahrick, A., \& Harris, M. (2009). Sexual side effects of antidepressant medications: An informed consent accountability gap. Journal of Contemporary Psychotherapy, 39(2), 135-143.

Baldwin, D. (2004). Sexual dysfunction associated with antidepressant drugs. Expert Opinion on Drug Safety, 3(5), 457-470.

Basson, R., Rees, P., Wang, R., Montejo, A. L., \& Incrocci, L. (2010). Sexual function in chronic illness. Journal of Sexual Medicine, 7(1), 374-388.

Bergvik, S., Sørlie, T., \& Wynn, R. (2010). Approach and avoidance coping and regulatory focus in patients having coronary artery bypass graft surgery. Journal of Health Psychology, 15(6), 915-924.

Brandtstädter, J., \& Renner, G. (1990). Tenacious goal pursuit and flexible goal adjustment: Explication and age-related analysis of assimilative and accommodative strategies of coping. Psychology and Aging, 5(1), 58-67.

Caching,T. \& Tiefer, L. (2012). Why Medicalisation? Introduction to the special issue on the medicalisation of sex. Journal of Sex Research, 49(4), 307-310.

Clayton A. \& Balon, R. (2009). The impact of mental illness and psychotropic medications on sexual functioning: The evidence and management (CME) (Vol. 6, p. 1200-1211): Wiley-Blackwell.

Davison, J., \& Huntington, A. (2010). "Out of sight": Sexuality and women with enduring mental illness. International Journal of Mental Health Nursing, 19(4), 240249.

Demyttenaere, K., \& Jaspers, L. (2008). Review: Bupropion and SSRI-induced side effects. Journal of Psychopharmacology, 22(7), 792-804. 
Dworkin, S. L., \& O'Sullivan, L. F. (2007). " It's Less Work for Us and It Shows Us She Has Good Taste. Masculinity, sexual initiation, and contemporary sexual scripts. In M. Kimmel (Ed.), The sexual self: The construction of sexual scripts, 105-121.

Farrell, J., \& Cacchioni, T. (2012). The medicalization of women's sexual pain. Journal of Sex Research, 49(4), 328-336.

Fisher, H., \& Thomson, A. (2006). Lust, attraction, attachment: Do side effects of serotonin-enhancing antidepressants jeopardize romantic love, marriage and fertility? In S. Platek (Ed.), Evolutionary cognitive neuroscience. Cambridge, MA: MIT Press.

Goffman, E. (1963). Stigma: Notes on the management of spoiled identity. Englewood Cliffs.

Grover,S., Shah, R.,Dutt, A. \& Avasthi, A (2012). Prevalence and pattern of sexual dysfunction in married females receiving antidepressants: An exploratory study. Journal of Pharmacology \& Pharmacotherapeutics, 3(3), 259-265.

Happell, B., Manias, E., \& Roper, C. (2004). Wanting to be heard: Mental health consumers' experiences of information about medication. International Journal of Mental Health Nursing, 13(4), 242-248.

Hayes, R. D. (2008). Assessing female sexual dysfunction in epidemiological studies: Why is it necessary to measure both low sexual function and sexuallyrelated distress? Sexual Health, 5, 215-218.

Hinchliff, S., Gott, M., \& Wylie, K. (2012). A qualitative study of heterosexual women's attempts to renegotiate sexual relationships in the context of severe sexual problems. Archives of Sexual Behavior, 41(5), 1253-1261.

Hollingworth, S. A., Burgess, P. M., \& Whiteford, H. A. (2010). Affective and anxiety disorders: Prevalence, treatment and antidepressant medication use. Australian \& New Zealand Journal of Psychiatry, 44(6), 513-519.

Holt R \& Slade P (2003). Living with an incomplete vagina and womb: An interpretative phenomenological analysis of the experiences of vaginal agenesis. Psychology, Health \& Medicine, 8(1), 19-33.

Lavie M., \& Willig, C. (2005). I don't feel like melting butter: An interpretative phenomenological analysis of the experience of inorgasmia. Psychology \& Heath 20(1), 115-128.

Lazarus, R. S., \& Folkman, S. (1984). Stress, appraisal, and coping. Springer Publishing Company.

Lehavot, K. (2012). Coping strategies and health in a national sample of sexual minority women. American Journal of Orthopsychiatry, 82(4), 494-504.

Liamputtong, P. (2013). Research methods in health: Foundations for evidencebased practice. South Melbourne, Vic.: Oxford University Press. 
Marriott C. \& Thompson A. (2008). Managing threats to femininity: Personal and interpersonal experience of living with vulval pain. Psychology and Health, 23(2), 243-258.

McCarthy, B., \& McDonald, D. (2009). Sex therapy failures: A crucial, yet ignored, issue. Journal of Sex \& Marital Therapy, 35(4), 320-329.

McCormick, N. B. (2010). Sexual scripts: Social and therapeutic implications. Sexual \& Relationship Therapy, 25(1), 96-120.

Metz, M. E., \& McCarthy, B. W. (2007). The "Good-Enough Sex" model for couple sexual satisfaction. Sexual and Relationship Therapy, 22(3), 351-362.

Mitchell, K., King, M., Nazareth, I., \& Wellings, K. (2011). Managing sexual difficulties: A qualitative investigation of coping strategies. Journal of Sex Research, 48(4), 325-333.

Mitchell, A. J., \& Selmes, T. (2007). Why don't patients take their medicine? Reasons and solutions in psychiatry. Advances in Psychiatric Treatment, 13(5), 336346.

Moret, C., Isaac, M., \& Briley, M. (2009 ). Review: Problems associated with longterm treatment with selective serotonin reuptake inhibitors. J Psychopharmacol, 23(8) 967-974.

Moreira, E. D., Glasser, D. B., King, R., Duarte, F. G., \& Gingell, C. (2008). Sexual difficulties and help-seeking among mature adults in Australia: results from the Global Study of Sexual Attitudes and Behaviours. Sexual Health, 5(3), 227-234.

Moynihan, R. (2003). The making of a disease: Female sexual dysfunction. British Medical Journal, 326, 45-47.

Nurnberg, H. G., Hensley, P. L., Heiman, J. R., Croft, H. A., Debattista, C., \& Paine, S. (2008). Sildenafil treatment of women with antidepressant-associated sexual dysfunction. Journal of the American Medical Association, 300(4), 395-404.

Nicholls, L. (2008). Putting the new view classification scheme to an empirical test. Feminism \& Psychology, 18(4), 515-526.

Quinn, C., Happell, B., \& Browne, G. (2012). Opportunity lost? Psychiatric medications and problems with sexual function: a role for nurses in mental health. Journal of clinical nursing, 21(3-4), 415-423.

Rosenberg, K. P., Bleiberg, K. L., Koscis, J., \& Gross, C. (2003). A survey of sexual side effects among severely mentally ill patients taking psychotropic medications: impact on compliance. Journal of Sex \&Marital Therapy, 29(4), 289-296. 
Safarinejad, M. R. (2011). Reversal of SSRI-induced female sexual dysfunction by adjunctive bupropion in menstruating women: A double-blind, placebo-controlled and randomized study. Journal of Psychopharmacology, 25(3), 370-378.

Saragoussi, D., Chollet, J., Bineau, S., Chalem, Y., \& Milea, D. (2012).

Antidepressant switching patterns in the treatment of major depressive disorder: A general practice research database (GPRD) study. International Journal of Clinical Practice, 66(11), 1079-1087.

Schweitzer, I., Maguire, K., \& Ng, C. (2009). Sexual side-effects of contemporary antidepressants: Review. The Australian and New Zealand Journal of Psychiatry, 43(9), 795-808.

Serretti, A., \& Chiesa, A. (2009). Treatment-emergent sexual dysfunction related to antidepressants: a meta-analysis. Journal of clinical psychopharmacology 29(3), 259-267.

Shifren, J. L., Johannes, C. B., Monz, B. U., Russo, P. A., Bennett, L., \& Rosen, R. (2009). Help-seeking behavior of women with self-reported distressing sexual problems. Journal of Women's Health, 18(4), 461-468.

Smith, J., Flowers, P.\& Larkin, M. (2009). Interpretative phenomenological analysis: Theory, method and research. Los Angeles: Sage.

Suls, J., \& Fletcher, B. (1985). The relative efficacy of avoidant and nonavoidant coping strategies: A meta-analysis. Health Psychology, 4(3), 249-288.

Sutherland, O. (2012). Qualitative analysis of heterosexual women's experience of sexual pain and discomfort. Journal of Sex \& Marital Therapy, 38(3), 223-244.

Taylor MJ, Rudkin L, Bullemor-Day P, Lubin J, Chukwujekwu C, Hawton K. (2013) Strategies for managing sexual dysfunction induced by antidepressant medication. Cochrane Database of Systematic Reviews, Issue 5. Art. No.: CD003382.

Tiefer, L. (2012). Medicalizations and demedicalizations of sexuality therapies. Journal of Sex Research, 49(4), 311-318.

Wiederman, M. W. (2005). The gendered nature of sexual scripts. The Family Journal, 13(4), 496-502.

Williams, V., Edin, H., Hogue, S., Fehnel, S. \& Baldwin, D. (2010). Prevalence and impact of antidepressant-associated sexual dysfunction in three European countries: Replication in a cross-sectional patient survey. Journal of Psychopharmacology, 24(4), 489-496.

Wong, A., Taylor, D. M., Ashby, K., \& Robinson, J. (2010). Changing epidemiology of intentional antidepressant drug overdose in Victoria, Australia. Australian and New Zealand Journal of Psychiatry, 44(8), 759-764.

Zhang, Y., Chow, V., Vitry, A. I., Ryan, P., Roughead, E. E., Caughey, G. E., \& Luszcz, M. A. (2010). Antidepressant use and depressive symptomatology among 
older people from the Australian longitudinal study of ageing. International Psychogeriatrics, 22(3), 437-444. 